This is a pre-published version of a chapter in a book available from Routledge:

https://www.routledge.com/Responsible-Global-Leadership-Dilemmas-Paradoxes-and-Opportunities/Mendenhall-

Zilinskaite-Stahl-Clapp-Smith/p/book/9781138049345.

Suggested citation: Reade, C. \& Lee, H-J. (2020). Geopolitics, social polarization, and the bridging role of cosmopolitan leaders. In M.E. Mendenhall, M. Zilinskaite, G.K. Stahl, \& R. Clapp-Smith (eds.), Responsible Global Leadership: Dilemmas, Paradoxes, and Opportunities. Routledge, pp. 29-44.

\title{
Geopolitics, Social Polarization, and the Bridging Role of Cosmopolitan Leaders
}

Carol Reade and Hyun-Jung Lee

\section{Introduction}

Recent political and social events around the world have displayed a mounting wave of antiglobalization, posing challenges for leaders of multinational enterprises (MNEs). The backlash against the movement of goods, capital, and people across borders has manifested in, or deepened, social divisions and nationalist sentiment in various countries around the world. In the US and in European countries, such as the United Kingdom and Germany, trade and immigration issues have fueled nationalist sentiment and hostility toward ethnic 'Others' (e.g., Gusterson, 2017). In South and Southeast Asia, such as Sri Lanka, Thailand, and Myanmar, Buddhist nationalism is on the rise over threats to identity posed in part by the globalization of ideas (Gravers, 2015). And on the African continent, xenophobic violence against migrants has been reported in South Africa (HIIK, 2018). The current global geopolitical landscape suggests that leaders of MNEs must be prepared to manage tensions arising from the polarization of political, ideological, religious, and/or ethnic social identities (e.g., Reade \& Lee, 2012).

Social polarization breeds social exclusion and a 'them and us' mentality (Tajfel \& Turner, 1979) that has implications for organizations, the way employees and other stakeholders are managed, and leadership competencies. Employees bring their beliefs and prejudices into the firm, and in so doing, the firm mirrors social divisions in society (Brief, Butz, \& Deitch, 2005). Challenges for the firm include reduced networking and information sharing among groups of employees, especially in situations of stark polarization, leading to compromised workplace integration at the organizational level (Lee \& Reade, 2015). While the firm mirrors social divisions, it is also the ideal place to foster intercultural understanding and inclusiveness and to create conditions for workplace harmony that can contribute to societal 'peace' (Reade, 2015). There is a growing awareness of an expanded role for firms, whereby they are not only an economic entity but also responsible for contributing to improving human well-being and social equity (Maak \& Pless, 2006; Stahl, Pless, \& Maak, 2013). Addressing the need of multiple stakeholders spanning across multiple operating contexts is particularly demanding, and it requires firms and managers to build social capital across boundaries and to balance the various, and often-conflicting, interests and expectations of different social and cultural groups. 
In this chapter, we highlight leaders' cosmopolitanism as a key to addressing such need. Cosmopolitanism is defined as an expansive identity horizon that transcends conventional social and cultural boundaries (Lee, 2015, p. 2). Given that the central tenet of cosmopolitanism is the capacity to embrace multiplicity in values, practices, and tastes by constantly transcending one's own familiar cultural boundaries (Lee, 2014; Levy, Lee, Jonsen, \& Peiperl, 2019), we refer to a cosmopolitan leader as a leader who exhibits high levels of such cosmopolitan disposition. We posit that cosmopolitan leaders are well positioned to transform and rewrite the 'rules of the game,' especially in times of profound social change (Adams, 2006; McNay, 1999). A significant development in the past few years relevant to leaders is on the geopolitical front, such as the global rise in political populism and nationalist sentiment. This is indicative of a global business environment that is increasingly volatile, uncertain, complex, and ambiguous (VUCA) (Miska, Economou \& Stahl, Chapter 1, this volume). We bring the influence of global political and social issues to the fore in our conceptualization of cosmopolitan leaders as exemplars of responsible global leadership and propose cosmopolitan leadership as microfoundations of societal peace.

We present a conceptual framework that highlights the reality and challenges of social polarization manifested in the workplace, and we offer research propositions that illustrate the role of cosmopolitan leaders to address those challenges. We suggest that cosmopolitanism is a competency for responsible global leadership, in that the building of inclusive workplaces and social harmony in the face of growing conflict worldwide can be considered a hallmark of corporate social responsibility. Theoretically, we draw on social identity theory (Tajfel \& Turner, 1979 ) to explain the phenomena of social polarization, social capital theory (Kwon \& Adler, 2014) to explain the mechanism underlying social integration in the workplace, and paradox theory (Schad, Lewis, Raisch, \& Smith, 2016; Smith \& Lewis, 2011) to illustrate how social polarization can be reframed from a dilemma into a paradox to unleash possibilities for constructive change and the promotion of pluralist societies. We thus highlight the very nature of cosmopolitan competencies as a key mechanism to help leaders bridge social divisions through balancing the paradoxes inherent in social dilemmas, navigate social tensions in a multicultural workplace, and promote positive intergroup relations. As a result, a cosmopolitan leader is likely to put practices into place that change the organizational climate to a more inclusive one and hence contribute to building intercultural understanding and inclusiveness in the wider society.

We aim to make three contributions. First, although the literature on responsible global leadership has provided advanced research frameworks, studies that focus on the sociopolitical aspects of leadership responsibility are still rare. Our study aims to contribute to the literature by including global political and social issues into the responsible global leadership conversation. Second, we propose cosmopolitanism as a key competency of responsible global leadership. Cosmopolitanism addresses the individual's transnational network position in its conceptualization (Levy et al., 2019) and thus reflects the global political and socioeconomic context, the realm of responsible global leaders. Third, by adopting a social identity, social capital, and paradox lens, we offer an in-depth analysis of how social polarization brought on by economic and cultural anxieties influenced by globalization can be approached constructively by firms and their leaders. 
In the following, we examine more closely the phenomenon of social polarization and the workplace as a crucible for social integration. Cosmopolitanism as a core competency for responsible global leadership is then introduced, along with our conceptual framework and research propositions.

\section{Social Polarization Through the Prism of Globalization}

We are witnessing today a geopolitical landscape that is riven by social division, political extremism, and nationalist sentiment (Inglehart \& Norris, 2016 Rodrik, 2018). These phenomena are often portrayed as being caused by globalization or the increasing interdependence and integration of the world economy (Hill \& Hult, 2017). Although this holds true in general, the picture is much more complex, because, across countries, historical and social issues may differ and because the effects of globalization are uneven (e.g., Osland, 2003; Rodrik, 2018). It has also been observed by anthropologists and others that the social divisions we currently see in society are not a new phenomenon but rather represent social injustices that have been present for some time (Rosa \& Bonilla, 2017). We therefore view social polarization through 'the prism' of globalization, acknowledging that globalization will cast a unique light and color on different national contexts, producing or accentuating social divisions on the basis of historically and culturally relevant phenomena.

\section{Economic and Cultural Anxiety}

Although national context and history produce differential effects of globalization across countries, a common thread appears to be economic and cultural anxiety experienced by some individuals over perceived threats to their livelihood and identity (Inglehart \& Norris, 2016; Rodrik, 2018). Polarized views over trade, immigration, and other issues are taking their toll on societies, including a breakdown in discourse between individuals, colleagues, and even families; political talks of separation from larger political unions; and mob violence between groups. Divisiveness in society can spawn misunderstanding and hatred between groups of people, leading to intergroup conflict and even war (Chirot, 2001). Globalization, in our view, 'stirs up' latent social problems that come to the surface and produce economic and cultural anxiety that manifests in social polarization. In other words, globalization accentuates the contrasts between people, or groups of people, such as differences in social class or ethnicity. Indeed, it has been recognized that the two fundamental divisions in society are "income/social class" differences and "ethno-national/cultural" differences (Rodrik, 2018). This is underscored by a study showing that economic interests, ideological or cultural concerns, and the national economy are important indicators of immigration sentiments (Wilkes, Guppy, \& Farris, 2008). The underlying economic and cultural anxieties can be intertwined in complex ways, and they manifest differently across countries.

Economic and cultural anxiety over one's livelihood and social standing in relation to others produces frustration and discontent. In other words, globalization highlights discontent in the status quo (or fear of change in the status quo) through comparison and contrast with the social or cultural 'Other.' As these concerns, or anxieties, enter the public discourse, debate ensues over the pros and cons of globalization, or more specifically free trade and mobility of 
people across borders. Whereas some see the benefits that open borders have provided, such as the availability of a variety of goods at affordable prices through imports and the increase in the talent pool through inward migration, others see a threat to their jobs and traditional culture. Research has shown the complexity around determining individual attitudes toward these issues, especially as they relate to immigration; for instance, there may be different reactions among individuals toward migrants versus refugees, and older people in general may be more opposed to immigrants than the young (O'Rourke \& Sinnot, 2006). Such divergence in people's beliefs over what is best for their country, their people, and themselves has led to the formation or crystallization of social groups that represent increasingly polarized worldviews.

The following offers recent examples of social polarization and nationalist sentiment that reflect economic and cultural anxieties influenced by globalization.

\section{Examples of Social Polarization and Nationalist Sentiment}

Social polarization and nationalist sentiment have consumed the attention of political observers, particularly since the vote in the United Kingdom to exit the European Union and in the same year the election of Donald Trump as president of the US. Although the outcomes in both cases caught many by surprise, subsequent analyses by political scientists and anthropologists highlighted social trends leading to these outcomes (e.g., Hobolt, 2016; Rosa \& Bonilla, 2017). When analysts dug below the surface, it became apparent that the nationalist 'our country first' response to immigration, imports, and job loss in both countries had struck a chord with an electoral base that swayed the vote in a seemingly unpredictable way. The rise of such nationalist sentiment exemplifies social polarization over issues that reflect economic and cultural anxiety through the prism of globalization. For instance, anti-Muslim sentiment has been prevalent at least since the terrorist events of September 11, 2001, in New York, and some equate immigrants, particularly those who are Muslim, with terrorists.

The trend of social polarization and nationalist sentiment is also evident in continental Europe. Following the Brexit vote, there have been political parties in European countries challenging the value of remaining in the European Union, which has fueled social polarization. The eurozone and migrant crises have served to deepen these divides (Hobolt, 2016). A study by Inglehart and Norris (2016) indicates that although economic issues are important drivers of social frustration, identity issues are more salient. Those authors conclude that cultural values provide the most support for voting patterns in Europe. That is, those who hold onto traditional values do not share the prevalent progressive values and feel threatened by them. As in the US, immigration has piqued economic and cultural anxiety among those who believe that immigrants not only take away jobs but threaten traditional culture. This includes anti-Muslim sentiments.

Nationalist sentiment reflecting economic and cultural anxiety has not been confined to Europe and the US. For instance, Buddhist nationalist sentiment has long existed in Myanmar (formerly Burma), Sri Lanka, Cambodia, and Thailand (Keyes, 2016). In recent years, there has been a rise in Buddhist nationalism, particularly in Myanmar and Sri Lanka, where social polarization has manifested in violence along religious and ethnic lines (Gravers, 2015). Extremist Buddhist groups in these Buddhist-majority countries have targeted Muslims because of economic and cultural anxiety (International Crisis Group, 2017). That is, there is fear among 
extremist Buddhist groups that the economic spoils of globalization are going to the Muslim 'Other' (Schonthal \& Walter, 2016) and a fear that Buddhism is in danger of being supplanted by other religions, particularly Islam, with implications for Buddhist culture and identity (Gravers, 2015).

Myanmar has been in the global spotlight for the violence perpetrated against the Rohingya ethnic group, the majority of whom are Muslim, leading to their mass exodus over the past few years (International Crisis Group, 2017). In Sri Lanka, extremist groups of the Buddhist majority began to target Muslim minorities in 2012, about the same time that Buddhist nationalism intensified in Myanmar. This suggests a connection between the monks of the two countries and shared identity politics (Gravers, 2015). Muslims are currently perceived to be the largest threat to the culture and economic opportunity of the Buddhists. Violent attacks on the Muslim minority in Sri Lanka have intensified, especially with the aid of social media, and in March 2018 prompted curfews, a government shutdown of social media, and a nationwide state of emergency (Keenan, 2018; Sirilal, 2018). These episodes have raised fears of a new round of communal violence in a country that is still recovering from a long religious and ethnic conflict during the civil war, which ended in 2009 (Sirilal, 2018). There is also concern that more violence could be incited through the spread of false rumors.

\section{A Social Identity Perspective}

Social identity theory (Tajfel \& Turner, 1979) provides a window into this phenomenon. There is a basic human tendency, according to the theory, for individuals to engage in social categorization as a means to elevate one's self-esteem through belonging to a group of similar others. Individuals strive for a positive self-concept that can be achieved through belonging to groups with distinctive attributes that uphold and reinforce one's beliefs and identity, such as age, gender, ethnicity, and worldview. Further, people are attracted to similar others because it is easier to communicate and build trust (e.g., Byrne, 1971). Consistent with social identity theory (Tajfel \& Turner, 1979), those in one's ingroup tend to be viewed favorably and trusted, whereas those in the outgroup tend to be viewed less positively (Pettigrew, 1998). When individuals surround themselves with similar others, individual and group beliefs can become entrenched, especially when the contrast with the 'Other' is made salient through derogatory social media characterizations and through other media channels that cater to the worldview of a particular group. This serves to fuel economic and cultural anxieties that can further perpetuate and deepen social polarization in a vicious circle, manifesting in an upsurge of nationalist sentiment and populism (e.g., Inglehart \& Norris, 2016).

These examples of social polarization and nationalist sentiment reflect economic and cultural anxieties influenced by globalization. Although such anxieties manifest in different social issues across national contexts, we can observe in these examples a refiguring and crystallization of group identities. In the US case, polarization has developed primarily between those who tend to see the benefits of open borders and those who tend to see open borders as a threat to their economic and cultural well-being. In the examples of Myanmar and Sri Lanka, social polarization has crystalized around ethnoreligious social identities where worldviews are constructed from membership in religious and ethnic communities. Although such social divisions may be long-standing in the respective societies, they appear to be exacerbated by the 
effects of globalization. The introduction of technology such as social media allows groups to spread messages that serve to heighten social identity and to further polarize groups, often with violent results.

Social polarization appears to be a sign of the times. As predicted by social identity theory, the implications of stark social polarization for intergroup relations are misunderstanding, animosity, or even war. The next section considers how polarized social identities play out at a micro-level in the workplace, and how the workplace can act as a grassroots arena for promoting social integration through the development of social capital that spans different social groups.

\section{The Workplace as a Crucible for Social Integration}

\section{Outside/Inside Mirroring Effects}

The workplace is a microcosm of society and, as such, mirrors social dynamics. This suggests that the nature of relationships between groups of people in society can affect relationships inside the organization (e.g., Pugh, Dietz, Brief \&Wiley, 2008). In other words, the societal context has an influence on employee attitudes and behavior in the workplace (Brief et al., 2005; Johns, 2006; Pugh et al., 2008). When a society is divided along political, ideological, or ethnoreligious lines, it stands to reason that such divisions may manifest inside the organization, with implications for the way employees relate to one another and for the functioning of the organization.

One manifestation of social polarization in the workplace is reduced networking and information sharing as a result of homophilous patterns of relationships on the basis of social identity groups (e.g., Lee \& Reade, 2015). This might be seen in employees of the same affinity group lunching together and socializing during breaks and after work. Such ingroup networking has ramifications for the organization. If individuals stick primarily to groups of people with whom they identify, the benefits of organizational networking and problem-solving become limited. Individuals will not be as inclined to seek information or to share information with those who are not part of their ingroup. In the case of countries with ethnic tensions accompanied with violence such as terrorism, the division and lack of interpersonal interaction across groups may be even more pronounced. Group members may avoid each other out of fear or may simply not be comfortable mingling with the 'cultural Other,' which further serves to reduce occupational networking in favor of networking with those in the 'safe' ingroup (Kastenmueller et al., 2011; Lee \& Reade, 2015).

Another workplace manifestation of social polarization can be sabotage. While the phenomenon of industrial sabotage is well known in the context of labor-management relations (e.g., Reade \& McKenna, 2009), sabotage in the workplace emanating from communal conflict can also occur. A study by Reade and McKenna (2007) highlighted a case where employees sabotaged the work of other employees who belonged to rival communal groups. This took place in the Sri Lankan subsidiary of a European MNE in the garment sector, where the action mirrored intergroup conflict in the community where the MNE subsidiary was located. The sabotage, which occurred over some period of time before it came to the notice of management, took the form of mis-cutting or mis-sewing pieces by members of one group that 
were needed by employees in the rival group to complete their work. The result for the organization was a slowing down of production, lower worker productivity, and, for the affected employees, lower payments since remuneration occurred on a piece-rate basis.

Another, related manifestation of polarized identities in the workplace may be lower trust among individuals who belong to different groups (Tajfel \& Turner, 1979). As social identity theory predicts, greater trust is accorded to members of the ingroup, and those of the outgroup are often treated with suspicion. Trust has implications for the functioning of the organization. A lack of trust between employees can curtail information sharing and collaborative innovation behavior among employees. Additionally, there are ramifications for leadership. If the leader is a member of one of the groups, whether a local manager or an expatriate, employees of the other group may perceive that they are not treated as favorably as the others. This can also be a challenge for expatriate leaders who are not members of either group but who have to balance the perspectives of both. Research shows that being perceived as an outgroup member by employees has a bearing on gaining the trust of the leader (Lee, Yoshikawa, \& Reade, 2018). This indicates that leaders in an era of social polarization should project a non-partisan outlook so as not to be perceived as the 'Other' by any social group. This also points to an intergroup leadership challenge of constructing relational identity among members of different social groups (Hogg, van Knippenberg, \& Rast, 2012).

\section{MNEs and Creating Cross-Boundary Social Capital}

While the workplace mirrors societal group divisions, along with the attendant challenges for interpersonal relations and organizational functioning, MNE workplaces are ideal for promoting social integration, including interethnic and intercultural integration. This is because MNEs bring together people from different social groups, representing different cultural backgrounds, social classes, and ethnicities. This may include migrants in the workplace and the need to foster their engagement and integration (Žilinskaitè \& Hajro, Chapter 6, this volume). There is an opportunity for MNE leaders to contribute to bridging differences at this grassroots level and to contribute toward a more plural and inclusive society through the creation of social capital across social boundaries that has benefits for the organization and for society at large.

Social capital is "the goodwill that is engendered by the fabric of social relations and that can be mobilized to facilitate action" (Adler \& Kwon, 2002, p. 17). Working in a MNE provides the opportunity to increase ties and bonds with individuals from different sociocultural groups, reflecting the structural and relational dimensions of social capital, respectively (Nahapiet \& Ghoshal, 1998). It also provides an opportunity to increase knowledge of cultural norms and practices of people from different social groups, reflecting the cognitive dimension of social capital (Nahapiet \& Ghoshal, 1998). Although the majority of studies on social capital focus on personal gains (e.g., Burt, 2004), such as enhanced job search and career advancement, other scholars (e.g., Coleman, 1990; Fukuyama, 1995) note that social capital can also constitute a public good, whereby one actor in society generates opportunities for others (Clement, Shipilov, \& Galunic, 2017). We propose that social capital developed in an MNE can promote positive intergroup relations within and outside the firm.

If a leader can nurture the development of social capital in the workplace that cuts across group boundaries, this should contribute to a positive intergroup climate in the 
organization, to more constructive communication, and to more positive intergroup and interpersonal relationships in the organization. This is echoed by Cameron and Caza (2005) whose work is linked to the positive organizational scholarship and responsible leadership literature. They point out that creating a positive organizational climate, fostering positive communication, and building positive relationships promotes social integration in the workplace. We consider these ideas in the context of MNEs faced with workplace interethnic or intercultural integration challenges.

A positive climate enhances prosocial behaviors, decision-making, productivity, and creativity (Cameron \& Caza, 2005; Staw \& Barsade, 1993). This can involve promoting the sense of value of what employees do on a day-to-day basis and linking that to identification with the employee's work unit and with the organization. If employees feel a sense of pride in their work, with the work unit, and with their organization, such positive attitudes are likely to have a beneficial effect on organizational climate that is conducive to social integration. When applied to MNEs faced with workplace interethnic or intercultural integration challenges, building social capital across ethnic and cultural boundaries becomes paramount. Studies have shown that creating a positive climate in a context of ethnic conflict, for example, involves providing employees with emotional support (Reade \& Lee, 2012) and using a collaborative conflict management style (Reade \& Lee, 2016). In the case of intercultural tensions, studies have shown that using indigenous management and leadership approaches consistent with the local cultural context signals respect, provides legitimacy to local values (Reade \& McKenna, 2013), and enhances employee commitment (Lee \& Reade, 2018).

Positive communication, such as affirmative and supportive language, has been found to create significantly more 'connectivity' in organizations, exchange of information, interpersonal interactions, and positive emotions (Cameron \& Caza, 2005, p. 97). A mixed-methods study by Lee et al. (2018) underscores the challenges of intercultural communication, and how communication can enhance trust when it is perceived positively. Interview data uncovered that explicit communication and openness to the local people and context (cosmopolitanism) were important to building positive relationships in the workplace and to gain and maintain trust among the local employees toward the expatriate leader. For instance, employees wanted more explanatory information behind decisions, clarification on roles and rewards, and more forthrightness in opinions and expressing true feelings. The findings from the interviews, which were supported with an empirical survey, suggest the importance of a positively perceived communication style in building relationships and trust in the MNE. We suggest that leaders can model positive communication themselves when working with individuals and groups.

Positive relationships foster compassion, forgiveness, and gratitude in organizations (Cameron \& Caza, 2005). Thus, building social capital across ethnic and cultural boundaries can reduce homophily (Lee \& Reade, 2015) and lead to reconciliation and social integration. An empirical study by Lee and Reade (2015) showed that in a societal context of violent ethnic conflict, positive relationships can be built in the workplace by following the prescriptions of contact theory (Allport, 1954; Pettigrew, Tropp, Wagner, \& Christ, 2011; Stathi \& Crisp, 2010). The results indicated that the perceived quality of work relationships and the degree of workgroup ethnic diversity matter for reducing perceptions of homophily, which can be detrimental to building positive relationships. The study demonstrated the continued validity of contact theory for MNEs operating in areas with ongoing ethnic conflict in terms of enhancing 
social integration in the workplace. We therefore suggest that leaders diversify their organizational workgroups and model positive relationship building themselves through the fair and equitable treatment of all employees.

In sum, we propose that the development of social capital in the workplace is integral to the promotion of workplace social integration and that it is a means to manage the 'outside/inside mirroring effects' in the organization. As elaborated next, we additionally propose that workplace social integration will in turn generate positive transfer effects to the wider society - what we refer to as 'inside/outside transfer effects.' Further, we propose that such efforts toward social integration require cosmopolitanism as a leadership competency.

\section{Cosmopolitanism as a Responsible Global Leadership Competency}

\section{The Nature of Cosmopolitanism}

Cosmopolitanism refers to an individual's acquired disposition that is characterized by an expanded identity horizon that transcends conventional local cultural boundaries (Lee, 2015). More specifically, the cosmopolitanism construct has two foundational elements that mutually reinforce one another: openness to the culturally different 'Other,' and transcendence of one's own cultural boundaries (Lee, 2014; Levy et al., 2019). On the one hand, openness facilitates individuals to engage with the culturally different 'Other' and to experience their cultures. Transcendence, on the other hand, allows individuals to experience their own cultures from afar (Szerszynski \& Urry, 2006) and helps them to reflect on their own cultures at a distance (Lee, 2014). This creates psychological space for individuals to take in and appreciate the cultures of others. Experiencing unfamiliar cultural systems, ideas, and people can induce meditation on one's own culture, which would usually not be called into question or reflection.

By engaging with multiple other cultures individuals can situate themselves in between multiple worlds. Such individuals are in a state of seeing their own culture as insider and outsider simultaneously. In the process of enacting multiple experiences of transcendence and openness, individuals with high cosmopolitanism can destabilize their cultural imprint (Adam, 2003), thereby projecting a hybridized or idiosyncratic cultural identity onto others, which is one of the consequences of reflexive modernity (Giddens, 1991). They are also able to develop and maintain a web of social networks and ties that are transnational and deterritorialized (Cohen, 1992; Giddens, 1990; Hess, 2004; Mau, Mewes, \& Zimmermann, 2008).

\section{The Bridging Role of Cosmopolitan Leaders}

We proposed earlier that MNEs could provide a grassroots arena for promoting social integration by providing opportunities for individuals to build social capital that spans different social, cultural, religious, and ethnic groups. We now consider the role of cosmopolitan leaders in bridging polarized social groups and facilitating the creation of boundary-crossing social capital. Drawing from the growing cosmopolitanism literature, we refer to cosmopolitan leadership behaviors as those characterized by the transcendence of one's conventional social and cultural boundaries and deep engagement with people from different social and cultural groups. Such cosmopolitan leadership behaviors will likely facilitate the development of 
employees' social capital (Nahapiet \& Ghoshal, 1998; Adler \& Kwon, 2002), especially social capital that cuts across social and cultural boundaries and contributes to positive workplace and societal outcomes. We suggest that cosmopolitan leadership through a bridging role serves as microfoundations of societal peace.

We propose that the bridging role of the cosmopolitan leader includes the ability to reframe social dilemmas as paradoxes, foster positive intergroup experiences in the workplace, and reconfigure social boundaries (see also Chapter 7 in this volume, by Jonsen, Orly, Toegel \& van Zanten). Figure 2.1 presents our conceptual framework. It highlights the societal, workplace, and individual challenges that arise from the current geopolitical landscape, the bridging role of the cosmopolitan leader, and the expected outcomes.

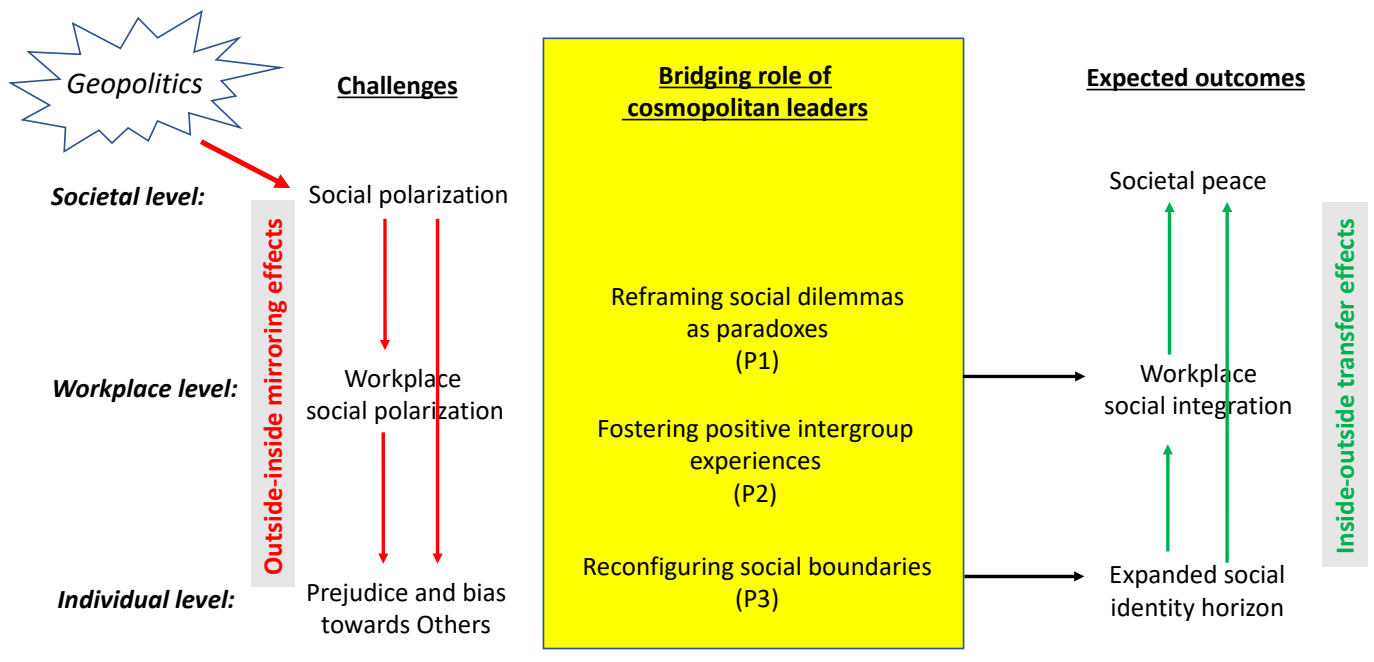

Figure 1. Conceptual framework of cosmopolitan leadership as microfoundations of societal peace

As shown, the expected outcomes include social integration at the workplace, an expanded social identity horizon for individuals, and societal peace. The proposed mechanism of the firm's contribution to societal peace is thus through diffusion of positive intergroup experiences, brokered by the cosmopolitan leader, from inside the workplace to society. We conceptualize this as 'inside/outside transfer effects.' Inside/outside transfer effects involve, firstly, reduced prejudice toward and increased tolerance of members of different social groups that one encounters in the workplace, resulting in positive work relationships; and, secondly, a reduction of prejudice toward members of different social groups that one encounters in society, even if such social groups are different from the ones involved in the intergroup encounter in the workplace (e.g., Crisp \& Turner, 2012; Schmid, Hewstone, Kuepper, Zick, \& Wagner, 2012), leading to greater societal peace. Cosmopolitanism, in our view, affords the leader the ability to facilitate social integration efforts and to orchestrate organizational actors in ways that promote not only workplace harmony but also peace in the wider society. The following presents our three research propositions, illustrating the bridging role of 
cosmopolitan leaders to transform the geopolitical challenges of social polarization into positive outcomes.

\section{Reframing Social Dilemmas as Paradoxes}

The crystallization of social identities around social dilemmas that stem from the economic and cultural anxieties brought on or exacerbated by the effects of globalization needs to be managed in a responsible way (Stahl \& Sully de Luque, 2014). In the examples of social polarization given earlier, the root of the division is over differing worldviews about what is needed for the country or the social group and its people to prosper (economic anxiety) and what is needed to protect the country and the social group from cultural others (cultural anxiety). Although these may be viewed as social dilemmas - that is, which way is the appropriate way to achieve the desired outcomes - we propose that such dilemmas can be fruitfully reframed as paradoxes. In other words, moving from an 'either/or' orientation to a 'both/and' orientation can help to address protracted differences that manifest in social polarization. Our key theoretical position is that reframing dilemmas as paradoxes is required for leaders to better promote social integration in their organizations and thus promote responsible global leadership. The paradox literature is illuminating in this regard.

Paradox theories (e.g., Lavine, 2014; Smith \& Lewis, 2011) consider the need for holistic approaches to managing the tensions between seeming opposites that are interdependent, such as the organizational tensions between collaboration and competition (Smith, Lewis, \& Tushman, 2016). They have arisen in response to the limitations of contingency theories that are concerned with choosing one alternative over another on the basis of contextual influences (Lawrence \& Lorsch, 1967). The 'either/or' approach of contingency theories does not address the growing need to embrace seeming opposites simultaneously (Lavine, 2014; Smith \& Lewis, 2011; Zhang, Waldman, Han, \& Li, 2015), and thus, its application remains limited in the management of complexities inherent in globalization. The examples of social polarization illustrated earlier capture the typical framing of such social issues as social dilemmas - that is, two seemingly opposing concerns about 'the economic prosperity and culture of our nation, our group' versus 'the economic prosperity and culture of the Other.' These social issues or dilemmas are presented as opposing and irreconcilable and are thus characterized as 'either/or.' By reframing such social issues as paradoxes, one is able to recognize that these seemingly opposite forces are interdependent and thus not something to be resolved but to be constantly balanced. The foundational characteristics of cosmopolitanism-cultural transcendence and openness - are likely to provide the keys to addressing this challenge. We propose that cosmopolitan leaders are well positioned to redefine such challenging social issues as paradoxes, because they are able to transcend conventional boundaries and hold a range of multiple views and values simultaneously. This leads to our first overarching proposition.

Proposition 1: Leaders who are high in cosmopolitanism are able to reframe social dilemmas as paradoxes by activating the rich and varied cultural resources they possess. 


\section{Fostering Positive Intergroup Experiences in the Workplace}

MNEs bring together individuals of diverse nationalities, ethnicities, and cultures. This results in a panoply of diverse tastes, interests, and worldviews - that is, a lack of a common culture. A common culture of shared meanings, tastes, and interests among individuals enables ties between individuals. When a common culture is absent among individuals, gaps in the cultural fabric emerge, and social actors, even those who are structurally or physically proximate, may be kept apart by deep divergences due to "cultural holes" (Pachucki \& Breige, 2010).

Cosmopolitans, responsible cosmopolitan leaders in particular, engage with others across cultural, social, and national boundaries with emotional and moral commitments (Skrbis, Kendall, \& Woodward, 2004). This enables them to bridge cultural holes (Levy et al., 2019) and manage conflictual relationships. In the context of bridging socially polarized groups, due to prejudice, bias, and animosity, parties often struggle to develop a shared understanding of the goals, essential tasks, and appropriate processes required for a fruitful collaboration. An empirical study by Lee and Reade (2015) showed that in a societal context of violent ethnic conflict, ethnicity provides a salient identity marker in the workplace, resulting in perceptions of ethnic homophily, which can be detrimental to building positive intergroup relationships between different social groups. A cosmopolitan leader with rich and varied cultural resources can bridge these incompatibilities by working with parties to transform their divergent interests and reach mutually acceptable solutions. This leads to the following proposition.

Proposition 2: Leaders who are high in cosmopolitanism are able to foster positive intergroup relations in the workplace by facilitating shared goals and common practices among employees from different social groups.

\section{Reconfiguring Social Boundaries}

We further propose that a cosmopolitan leader can reconfigure social boundaries in the workplace by introducing relevant alternative identity boundaries. This could include a range of social identities around shared interests in local and global issues. By strategically creating opportunities for employees to shift between multiple group boundaries, the salience of seemingly intractable social categories may weaken, and new social identities that cut across pre-existing social categories may emerge. There is evidence to show that the MNE can provide an alternative social identity base for local employees in societal contexts of violent intergroup conflict, thus possibly attenuating the ethnicity-based social division experienced at the societal level (Reade \& Lee, 2012). This is crucial for leaders of MNEs in the current geopolitical climate of nationalist sentiment and polarized social identities and the hallmark, we believe, of a responsible global leader in today's fractious world. All in all, an alternative identity base will ultimately help individuals to experience positive intergroup relations in the workplace and to diminish prejudices, biases, and animosity toward the social and cultural Other perceived to stand at the opposite pole of the political, ideological, ethnic, and/or religious spectrum. In turn, this will provide new impetus for tolerance and understanding toward the Other. This leads to the following proposition on how cosmopolitan leaders reconfigure social boundaries. 
Proposition 3: Leaders who are high in cosmopolitanism are able to reconfigure social boundaries in the workplace by creating opportunities for employees to experience alternative social identities that cut across pre-existing social categories.

\section{Conclusion}

The growing trend of anti-globalization and rise in nationalist sentiment and social polarization around the world create new challenges for organizations and leaders. These geopolitical developments compromise societal well-being and peace with ramifications for social integration at the organizational level. Societal peace is considered to be among the world's grand challenges, alongside poverty and climate change. All of these issues, which are encapsulated in the United Nations Sustainable Development Goals (SDGs), are increasingly important for leaders and companies (e.g., Reade, Todd, Osland, \& Osland, 2008). This is underscored by recent calls for scholarship to examine the role of organizations to address these grand challenges (Buckley, Doh, \& Benischke, 2017; George, Howard-Grenville, Joshi, \& Tihanyi, 2016). The United Nations also calls on the private sector to collaborate with governments and NGOs to help achieve the 17 SDGs. For instance, SDG \#16 provides guidance to businesses on how to promote peaceful and inclusive societies for sustainable development. Responsible global leadership is needed for the promotion of peaceful and inclusive societies, and we have proposed that cosmopolitanism is a competency required of leaders to meet this challenge.

Geopolitical trends, as we have illustrated, adversely affect societies, workplaces, and individuals. We have highlighted social identity theory as the mechanism underlying social polarization, social capital theory as the mechanism underlying social integration, and paradox theory to explain the reframing of social dilemmas as a critical component for the cosmopolitan leader to bridge social divisions and orchestrate actors toward more socially integrated workplaces. The specific challenges that we identified are social polarization at the societal level, stemming from economic and cultural anxieties stirred up by globalization and leading to nationalist sentiment. Social polarization, along with individual-level prejudices and biases toward others, is mirrored in the workplace, or what we refer to as outside/inside mirroring effects. In the workplace, the cosmopolitan leader engages in behaviors and actions to bridge polarized social groups and to transform the climate of the workplace. The leader reframes social dilemmas as paradoxes, fosters positive intergroup relations, and reconfigures social boundaries in the workplace.

The outcomes of the cosmopolitan leader's bridging role are reflected in what we refer to as inside/outside transfer effects. These include social integration in the workplace, enhanced understanding among individuals through their expanded identity horizons, and ultimately greater societal peace. We have suggested, for instance, that a cosmopolitan leader could model perspective taking, putting enlightened practices into place that could change the climate not only internal to the company but potentially outside of the company (Lee \& Reade, 2015; Reade, 2015). Through inside/outside transfer effects, employees are likely to exhibit more openness or cosmopolitan practice outside the organization, which can translate to more peaceful intergroup encounters in society. In this way, cosmopolitan leaders, through their 
behaviors and actions in the workplace, constitute microfoundations of societal peace in a geopolitical era of social polarization.

The role of business in fostering peaceful societies has been recently included among responsible corporate practices where the firm enters the political realm (Fort \& Schipani, 2004; Oetzel, Westermann-Behaylo, Koerber, Fort, \& Rivera, 2010; Scherer \& Palazzo, 2011). Over the past few decades, much has been written on the responsibility of the firm to engage in activities that go beyond seeking profit (e.g., Waddock, Bodwell, \& Graves, 2002). Further, in light of the world's pressing issues, and because MNEs have substantial power and resources, there has been stakeholder pressure on MNEs to give back to the communities in which they are located, beyond charitable action (Maak, Pless, \& Voegtlin, 2016). This includes promoting societal peace (Fort \& Schipani, 2004; Oetzel et al., 2010; Reade, 2015), alongside other activities, such as promoting public health, education, and the protection of human rights and the environment (Scherer \& Palazzo, 2011; Shrivastava, 2008). In our conceptual framework, we bring the influence of global political and social issues to the fore in our conceptualization of cosmopolitan leaders as exemplars of responsible global leadership.

\section{References}

Adam, B. (2003). Reflexive modernization temporalized. Theory, Culture \& Society, 20(2), 59-78. Adams, M. (2006). Hybridizing habitus and reflexivity: Towards an understanding of contemporary identity? Sociology, 40(3), 511-528.

Adler, P. S., \& Kwon, S-W. (2002). Social capital: Prospects for a new concept. Academy of Management Review, 27(1), 17-40.

Allport, G. W. (1954). The nature of prejudice. Cambridge, MA: Perseus Books.

Brief, A. P., Butz, R. M., \& Deitch, E. A. (2005). Organizations as reflections of their environments: The case of race composition. In R. Dipboye \& A. Colella (Eds.), Discrimination at work: The psychological and organizational bases (pp. 119-148). Mahwah, NJ: Erlbaum.

Buckley, P. J., Doh, J. P., \& Benischke, M. H. (2017). Towards a renaissance in international business research? Big questions, grand challenges, and the future of IB scholarship. Journal of International Business Studies, 48, 1045-1064.

Burt, R. S. (2004). Structural holes and good ideas. American Journal of Sociology, 110 (2), 349300.

Byrne, D. (1971). The attraction paradigm. New York: Academic Press.

Cameron, K., \& Caza, A. (2005). Developing strategies and skills for responsible leadership. In J. P. Doh \& S. A. Stumpf (Eds.), Handbook on responsible leadership and governance in global business (pp. 87-111). Northampton, MA: Edward Elgar.

Chirot, D. (2001). Introduction. In D. Chirot \& M. S. Seligman (Eds.), Ethnopolitical warfare: Causes, consequences, and possible solutions (pp. 3-26). Washington, DC: American Psychological Association.

Clement, J, Shipilov, A., \& Galunic, C. (2017). Brokerage as a public good: The externalities of network hubs for different formal roles in creative organizations. Administrative Science Quarterly, 63(2), 251-286. 
Cohen, M. (1992). Rooted cosmopolitanism: Thought on the left, nationalism, and multiculturalism. Dissent, 39, 478-483.

Coleman, J. S. (1990). Social capital in the creation of human capital. American Journal of Sociology, 94(Suppl), 95-120.

Crisp, R. J., \& Turner, R. N. (2012). The imagined contact hypothesis. Advances in Experimental Social Psychology, 46, 125-182.

Fort, T. L., \& Schipani, C. A. (2004). The role of business in fostering peaceful societies. Cambridge, UK: Cambridge University Press.

Fukuyama, F. (1995). Trust: The social virtues and the creation of prosperity. New York: Free Press.

George, G., Howard-Grenville, J., Joshi, A., \& Tihanyi, L. (2016). Understanding and tackling societal grand challenges through management research. Academy of Management Journal, 59(6), 1880-1895.

Giddens, A. (1990). The consequences of modernity. Cambridge, England: Polity press.

Giddens, A. (1991). Modernity and self-identity: Self and society in the late modern age. Stanford, CA: Stanford University Press.

Gravers, M. (2015). Anti-Muslim Buddhist nationalism in Burma and Sri Lanka: Religious violence and globalized imaginaries of endangered identities. Contemporary Buddhism, 16(1), 1-27.

Gusterson, H. (2017). From Brexit to Trump: Anthropology and the rise of nationalist populism. American Ethnologist, 44(2), 209-214.

Heidelberg Institute for International Conflict Research (HIIK). (2018). Conflict barometer 2017. Department of Political Science, University of Heidelberg Press.

Hess, M. (2004). "Spatial" relationships? Towards a reconceptualization of embeddedness. Progress in Human Geography, 28, 165-186.

Hill, C., \& Hult, T. (2017). International business: Competing in the global marketplace (11th ed). New York: McGraw-Hill.

Hobolt, S. B. (2016). The Brexit vote: A divided nation, a divided continent. Journal of European Public Policy, 23(9), 1259-1277.

Hogg, M. A., van Knippenberg, D., \& Rast III, D. E. (2012). Intergroup leadership in organizations: Leading across group and organizational boundaries. Academy of Management Review, 37(2), 232-255.

Inglehart, R. F., \& Norris, P. (2016). Trump, Brexit, and the rise of populism: Economic have-nots and cultural backlash. Harvard Kennedy School, Faculty Working Paper Series, RWP-026.

International Crisis Group. (2017). Buddhism and state power in Myanmar. Retrieved September 13, 2018 from www.crisisgroup.org/asia/south-east-asia/myanmar/290buddhism-and-state-power-myanmar

Johns, G. (2006). The essential impact of context on organizational behavior. Academy of Management Review, 31, 386-408.

Kastenmueller, A., Greitemeyer, T., Aydin, N., Tattersall, A. J., Peus, C., Bussmann, P., . ., Fischer, P. (2011). Terrorism threat and networking: Evidence that terrorism salience decreases occupational networking. Journal of Organizational Behavior, 32, 961-977.

Keenan, A. (2018, March 7). 'Islamaphobic narratives' inflame Sri Lanka communal tensions. Sri Lanka Brief. Retrieved September 13, 2018, from 
http://srilankabrief.org/2018/03/islamophobic-narratives-inflame-sri-lanka-communaltensions-alan-keenan/

Keyes, C. (2016). Theravada Buddhism and Buddhist nationalism: Sri Lanka, Myanmar, Cambodia, and Thailand. The Review of Faith \& International Affairs, 14(4), 41-52.

Kwon, S-W., \& Adler, P. S. (2014). Social capital: Maturation of a field of research. Academy of Management Review, 39(4), 412-422.

Lavine, M. (2014). Paradoxical leadership and the competing values framework. The Journal of Applied Behavioral Science, 50(2), 189-205.

Lawrence, P. R., \& Lorsch, J. W. (1967). Organizations and environment: Managing differentiation and integration. Homewood, IL: Irwin.

Lee, H-J. (2014). Identities in the global world of work. In B. Gehrke \& M-T. Claes (Eds.), Global leadership practices: A cross-cultural management perspective (pp. 85-101). London: Palgrave Macmillan.

Lee, H-J. (2015). Cosmopolitanism. In Wiley encyclopedia of management (Vol. 6, 3rd ed., pp. 12). London: Wiley.

Lee, H-J., \& Reade, C. (2015). Ethnic homophily perceptions as an emergent IHRM challenge: Evidence from firms operating in Sri Lanka during the ethnic conflict. The International Journal of Human Resource Management, 26, 1645-1664.

Lee, H-J., \& Reade, C. (2018). The role of yin-yang leadership and cosmopolitan followership in fostering employee commitment in China: A paradox perspective. Cross Cultural and Strategic Management, 25(2), 276-298.

Lee, H-J., Yoshikawa, K., \& Reade, C. (2018). Intercultural communication challenges in East-East encounters. Best Paper Proceedings of Academy of Management Annual Meeting, Chicago, IL.

Levy, O., Lee, H-J., Jonsen, K., \& Peiperl, M. (2019). Transcultural brokerage: The role of cosmopolitans in bridging structural and cultural holes. Journal of Management, 45(2), 417-450.

Maak, T., \& Pless, N. M. (2006). Responsible leadership in a stakeholder society-A relational perspective. Journal of Business Ethics, 66, 99-115.

Maak, T., Pless, N. M., \& Voegtlin, C. (2016). Business statesman of shareholder advocate? CEO responsible leadership styles and the micro-foundations of political CSR. Journal of Management Studies, 53(3), 463-493.

Mau, S., Mewes, J., \& Zimmermann, A. (2008). Cosmopolitan attitudes through transnational social practices? Global Networks, 8, 1-24.

McNay, L. (1999). Gender, habitus and the field: Pierre Bourdieu and the limits of reflexivity. Theory, Culture \& Society, 16(1), 95-117.

Nahapiet, J., \& Ghoshal, S. (1998). Social capital, intellectual capital, and the organizational advantage. Academy of Management Review, 23(2), 242-266.

Oetzel, J., Westermann-Behaylo, M., Koerber, C., Fort, T. L., \& Rivera, J. (2010). Business and peace: Sketching the terrain. Journal of Business Ethics, 89, 351-373.

O'Rourke, K. H., \& Sinnott, R. (2006). The determinants of individual attitudes towards immigration. European Journal of Political Economy, 22, 838-861.

Osland, J. S. (2003). Broadening the debate: The pros and cons of globalization. Journal of Management Inquiry, 12(2), 137-154. 
Pachucki, M. A., \& Breige, R. L. (2010). Cultural holes: Beyond relationality in social networks and culture. Annual Review of Sociology, 36, 205-224.

Pettigrew, T. F. (1998). Intergroup contact theory. Annual Review of Psychology, 49(1), 65-85.

Pettigrew, T. F., Tropp, L. R., Wagner, U., \& Christ, O. (2011). Recent advances in intergroup contact theory. International Journal of Intercultural Relations, 35, 271-280.

Pugh, S. D., Dietz, J., Brief, A., \& Wiley, J. W. (2008). Looking inside and out: The impact of employee and community demographic composition on organizational diversity climate. Journal of Applied Psychology, 93, 1422-1428.

Reade, C. (2015). Firms as 'peaceful oases': Conceptualizing the role of conflict-sensitive human resource management. Business, Peace and Sustainable Development, 5, 7-28.

Reade, C., \& Lee, H-J. (2012). Organizational commitment in time of war: Assessing the impact and attenuation of employee sensitivity to ethnopolitical conflict. Journal of International Management, 18, 85-101.

Reade, C., \& Lee, H-J. (2016). Does ethnic conflict impede or enable employee innovation behavior? The alchemic role of collaborative conflict management. International Journal of Conflict Management, 27(2), 199-224.

Reade, C., \& McKenna, M. (2007). From antiquity to the factory floor: Reviving 'original dispute resolution' in the Sri Lankan subsidiary of a multinational enterprise. International Journal of Conflict Management, 18(2), 108-127.

Reade, C., \& McKenna, M. (2009). Seeding the clouds for industrial relations climate change in emerging economies. Thunderbird International Business Review, 51(2), 125-141.

Reade, C., \& McKenna, M. (2013). Leveraging indigenous knowledge for sustainable workplace harmony: A conflict management tool for international managers. The Journal of Corporate Citizenship, 51, 53-71.

Reade, C., Todd, A-M., Osland, A., \& Osland, J. S. (2008). Poverty and the multiple stakeholder challenge for global leaders. Journal of Management Education, 32(6), 820-840.

Rodrik, D. (2018). Populism and the economics of globalization. Journal of International Business Policy, 1, 12-23.

Rosa, J., \& Bonilla, Y. (2017). Deprovincializing Trump, decolonizing diversity, and unsettling anthropology. American Ethnologist, 44(2), 201-208.

Schad, J., Lewis, M. W., Raisch, S., \& Smith, W. K. (2016). Paradox research in management science: Looking back to move forward. Academy of Management Annals, 10(1), 5-64.

Scherer, A. G., \& Palazzo, G. (2011). The new political role of business in a globalized world: A review on a new perspective on CSR and its implications for the firm, governance, and democracy. Journal of Management Studies, 48(4), 889-931.

Schmid, K., Hewstone, M., Kuepper, B., Zick, A., \& Wagner, U. (2012). Secondary transfer effects of intergroup contact: A cross-national comparison in Europe. Social Psychology Quarterly, 75(1), 28-51.

Schonthal, B., \& Walton, M. J. (2016). The (new) Buddhist nationalisms? Symmetries and specificities in Sri Lanka and Myanmar. Contemporary Buddhism, 17(1), 81-115.

Shrivastava, P. (2008). Corporate citizenship and the environment. In A. G. Scherer \& G. Palazzo (Eds.), Handbook of research on corporate citizenship (pp. 166-184). Cheltenham, UK: Edward Elgar. 
Sirilal, R. (2018, March 7). Sri Lanka arrests 10 for anti-Muslim violence as towns smolder. Reuters World News. Retrieved September 13, 2018, from www.reuters.com/article/ussri-lanka-clashes/sri-lanka-arrests-10-for-anti-muslim-violence-as-towns-smolderidUSKCN1GKOFB

Skrbis, Z., Kendall, G., \& Woodward, I. (2004). Locating cosmopolitanism: Between humanist ideal and grounded social category. Theory, Culture \& Society, 21(6), 115-136.

Smith, W. K., \& Lewis, M. W. (2011). Toward a theory of paradox: A dynamic equilibrium model of organizing. Academy of Management Review, 36(2), 381-403.

Smith, W. K., Lewis, M. W., \& Tushman, M. L. (2016, May). “Both/and” leadership. Harvard Business Review, 2-8.

Stahl, G. K., Pless, N. M., \& Maak, T. (2013). Responsible global leadership. In M. E. Mendenhall et al. (Eds.), Global leadership: Research, practice, and development (2nd ed.). London: Routledge.

Stahl, G. K., \& Sully de Luque, M. (2014). Antecedents of responsible leader behavior: A research synthesis, conceptual framework, and agenda for future research. Academy of Management Perspectives, 28(3), 235-254.

Stathi, S., \& Crisp, R. J. (2010). Intergroup contact and the projection of positivity. International Journal of Intercultural Relations, 34, 580-591.

Staw, B., \& Barsade, S. (1993). Affect and managerial performance: A test of the sadder-butwiser vs. happier-and-smarter hypotheses. Administrative Science Quarterly, 38(2), 304331.

Tajfel, H., \& Turner, J. C. (1979). An integrative theory of intergroup conflict. In W. G. Austin \& S. Worchel (Eds.), The social psychology of intergroup relations (pp. 33-37). Monterey, CA: Brooks/Cole.

Waddock, S. A., Bodwell, C., \& Graves, S. B. (2002). Responsibility: The new business imperative. Academy of Management Executive, 16(2), 132-148.

Wilkes, R., Guppy, N., \& Farris, L. (2008). 'No thanks, we're full': Individual characteristics, national context, and changing attitudes toward immigration. International Migration Review, 42(2), 302-329.

Zhang, Y., Waldman, D. A., Han, Y-L., \& Li, X-B. (2015). Paradoxical leader behaviors in people management: Antecedents and consequences. Academy of Management Journal, 58(2), 538-566. 